\title{
Impact of scouring on quality parameters of banana pseudostem fibres
}

\author{
RENUKA I. GANIGER AND JYOTI V. VASTRAD
}

Received: 31.01.2017; Revised: 24.03.2017; Accepted: 10.04.2017

See end of the paper for authors' affiliations

\section{RENUKA I. GANIGER}

All India Co-ordinated Research Project on Home Science (Clothing and

Textiles), Main Agricultural Research

Station, University of Agricultural

Sciences, DHARWAD (KARNATAKA)

INDIA

Email : renukaiganiger@gmail.com
ABSTRACT : In recent years, the search for alternative sources of fibres has been increased due to the growing shortage of fibres, where in banana is one among them. Banana plant is highly valued for its fruit, but it also yields vast quantities of biomass. Banana fibres are the essential alternative even expanding the horizon of textiles and they are non-toxic in nature. However, the present study is the outcome of the varieties (Grand Naine and Ney Poovan) of the pseudostem. Research work carried out to know the effect of scouring on strength, elongation and fineness of banana pseudostem fibre. The fibres extracted from pseudostem of banana plant varieties (Grand Naine and Ney Poovan) mechanically using raspador machine. Scouring is one of the most essential processes that are carried out for the natural fibres to remove the unwanted impurities and then vegetable matter. It further enhances the fibre qualities like strength and lustre. The fibres were scoured with 1 per cent, 2 per cent, 3 per cent and 4 per cent $\mathrm{NaOH}$ solution at boiling for 45 minutes and finally treated with acetic acid for neutralization, washed thoroughly in plain water and shade dried. The samples were tested for strength and elongation using single yarn tester and fineness was tested using gravimetric method. Results revealed that the fibre scoured with 1 per cent $\mathrm{NaOH}$ exhibited higher strength than the control and other concentrations; whereas elongation is found to be higher in 1 per cent and fineness parameters of the treated with 4 per cent concentration of $\mathrm{NaOH}$ to be higher than the other samples. Fibres can be utilized in the preparation of value added products and fashion accessories using braiding and carding technique.

KEY WORDS: Banana pseudostem, Biomass, Fibre, Raspador machine, Scouring

- HOW TO CITE THIS PAPER : Ganiger, Renuka I. and Vastrad, Jyoti V. (2017). Impact of scouring on quality parameters of banana pseudostem fibres. Asian J. Home Sci., 12 (1) : 60-68, DOI: 10.15740/HAS/ AJHS/12.1/60-68. 